\section{ОПРЕАЕАЕНИЕ ФАКТОРОВ,} СПОСОБСТВУЮЩИХ РЕТЕНЦИИ КАЫКОВ ВЕРХНЕЙ ЧЕАЮСТИ У АЕТЕЙ В СМЕННОМ ПРИКУСЕ

Ретенированными называются зубы, остановившиеся в своем прорезывании в челюсти [7]. Наиболее часто встречается ретенция клыков - 51,1\% среди ретенированных комплектных зубов [5]. Наличие клыков верхней челюсти в зубном ряду играет огромную роль как в обеспечении полноценной функциональной окклюзии, так и в формировании эстетики улыбки [2].

По данным литературы, отмечается увеличение частоты обращаемости пациентов с ретенцией клыков верхней челюсти $[2,4,5]$. По нашим данным, эта цифра составила 7\% случаев от числа всех пациентов с зубочелюстной патологией [8]. Ортодонтическое лечение данной группы пациентов является сложным и продолжительным, оно требует проведения дополнительных рентгенологических исследований, хирургических вмешательств [4]. В среднем этап экструзии ретенированных клыков увеличивает продолжительность ортодонтического лечения на шесть месяцев [8].

Существует много публикаций, посвященных особенностям комплексного лечения данной аномалии, однако вопросам профилактики ретенции клыков верхней челюсти уделено мало внимания $[1,2,4,5]$. По нашему мнению, причины, приводящие к возникновению ретенции клыков верхней челюсти, необходимо искать в период сменного прикуса. У современных детей часто бывают нарушены закономерности естественной смены зубов, такие как парность, симметричность, последовательность, сроки [3]. Эти нарушения могут привести к ретенции клыков верхней челюсти, так как их прорезывание завершает смену зубов опорной зоны.

Возникновение ретенции зубов увеличивает число пациентов с зубочелюстными аномалиями в целом. Тогда как своевременно проведенное рентгенологическое исследование может выявить показания к удалению персистентных зубов и предупредить эту проблему.

\section{Цель исследования}

Выявить нарушения закономерностей смены зубов у детей в период сменного прикуса.

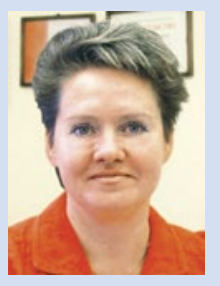

Мягкова Н.В.

к.м.н., доцент кафедры стоматологии детского возраста и ортодонтии ГБОУ ВПО УГМУ, г. Екатеринбург, kdvo@inbox.ru

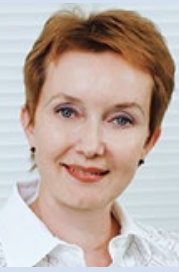

Бимбас Е.C. д.м.н., проф., зав. кафедрой стоматологии детского возраста и ортодонтии УГМУ, г. Екатеринбург, kdvo@inbox.ru

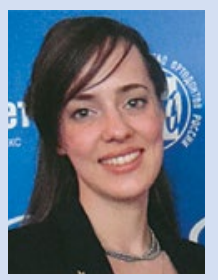

Сайпеева М.М. врач-ортодонт, ассистент кафедры стоматологии детского возраста и ортодонтии ГБОУ ВПО УГМУ, г. Екатеринбург, marybel@bk.ru

\section{Резюме}

В статье представлены результаты обследования 120 школьников в возрасте от 7 до 12 лет. Анализируются нарушения всех закономерностей природной смены зубов у большинства детей. Эти нарушения могут привести к возникновению ретенции клыков верхней челюсти.

Ключевые слова: ретенированные зубы, нарушения закономерностей смены зубов, ранний сменный прикус.

DEFINITION FACTORS OF MAXILLA CANINES RETENTION AT CHILDREN IN A REPLACEABLE BITE

Myagkova N.V., Bimbas E.S., Sipeeva M.M.

\section{The summary}

In this research results of inspection of 120 school students aged from 7 till 12 years are presented. The analysis defined violation of all regularities of natural change of teeth at the majority of children. These violations can lead to formation of maxilla canines retention.

Keywords: impacted teeth, tooth replacement patterns of violations, the early mixed dentition. 


\section{Материалы и методы}

Всего на базах общеобразовательных учебных заведений в г. Екатеринбурге было обследовано 120 школьников в возрасте от 7 до 12 лет. Ориентируясь на имеющиеся в литературе сроки смены зубов, обследуемые дети были разделены нами на две группы:

1. Младшая группа (80 человек в возрасте 7-8 лет) - ранний сменный прикус (сменный - I прикус);

2. Старшая группа (40 человек в возрасте 11-12 лет) - поздний сменный прикус (сменный - II прикус).

Данные обследования вносились в индивидуальную карту обследования, включающую:

Определение закономерности смены зубов:

- парность;

- симметричность;

- последовательность;

- сроки.

Оценка состояния зубов и уровень гигиены полости рта:

- интенсивность кариеса (КПУ+кп);

- индексная оценка гигиены (ИГР-У).

Статистическая обработка данных проводилась с использованием программы Microsoft Excel 2003.

\section{Материалы и их обсуждение}

При осмотре детей младшей группы (7-8 лет) в раннем сменном прикусе определялось наличие постоянных первых моляров и резцов. В семилетнем возрасте первые постоянные моляры определялись у девочек в $92,3 \%$ случаев и у мальчиков в $96,8 \%$ случаев (рис. 1). К восьми годам прорезывание первых моляров определялось в $100 \%$ случаев как у мальчиков, так и у девочек. При этом симметричность и парность прорезывания этих зубов не нарушена, объективные сроки прорезывания укладываются в стандартные нормы.

Структура смены резцов представлена в табл. 1. При анализе данных таблицы можно отметить, что смена центральных и боковых резцов нижней челюсти протекает симметрично и практически завершается к 8 годам, что не противоречит стан- дартным срокам прорезывания этих зубов. Смена зубов во фронтальном отделе верхней челюсти характеризуется полным прорезыванием центральных резцов к 8 годам как у девочек, так и у мальчиков. Боковые резцы у мальчиков к этому возрасту меняются только в $66,7 \%$ случаев, тогда как у девочек этот процесс ускорен и постоянные боковые резцы определяются в 77,8\% случаев, но этот процесс происходит несимметрично (табл. 1, рис. 2).

Наличие молочных резцов выявлено в 22,2\% случаев у девочек и в $33,3 \%$ случаев у мальчиков в возрасте восьми лет, что может быть оценено как нарушение физиологической резорбции корней молочных зубов.

Интенсивность кариозного процесса в данной группе пациентов высокая и составляет 4,81, на фоне неудовлетворительной гигиены полости рта ИГР-У составляет 1,73. На наш взгляд, данный факт приводит к высокому количеству ранних удалений молочных зубов опорной зоны. Почти у половины обследованных детей, в 45,6\% случаев, есть удаленные молочные клыки и моляры. Причем у 20,3\% из их числа удалено два и более зубов.

Раннее удаление молочных зубов опорной зоны у детей 7-8 лет приводит к нарушению прорезывания постоянных зубов. Преждевременное прорезывание постоянных премоляров выявлено у $12,7 \%$ детей. В $32,5 \%$ случаев при раннем удалении определено смещение имеющихся зубов в сторону дефекта (рис. 3).

Таким образом, в раннем сменном прикусе наблюдается целый ряд нарушений закономерностей

Таблииа 1

Структура смены резцов у детей 7-8 лет

\begin{tabular}{|c|c|c|c|c|c|c|c|}
\hline \multicolumn{4}{|c|}{ Девочки 7 лет } & \multicolumn{4}{c|}{ Мальчики 7 лет } \\
\hline $3.1 / 4.1$ & $3.2 / 4.2$ & $1.1 / 2.1$ & $1.2 / 2.2$ & $3.1 / 4.1$ & $3.2 / 4.2$ & $1.1 / 2.1$ & $1.2 / 2.2$ \\
\hline $100 / 100$ & $86,7 / 86,7$ & $100 / 100$ & $46,7 / 60,0$ & $96,8 / 96,8$ & $71,0 / 71,0$ & $83,9 / 90,3$ & $32,3 / 38,7$ \\
\hline \multicolumn{3}{|c|}{ Девочки 8 лет } & \multicolumn{5}{c|}{ Мальчики 8 лет } \\
\hline $100 / 100$ & $100 / 100$ & $94,4 / 100$ & $66,7 / 88,9$ & $100 / 100$ & $93,3 / 100$ & $100 / 93,3$ & $66,7 / 66,7$ \\
\hline
\end{tabular}

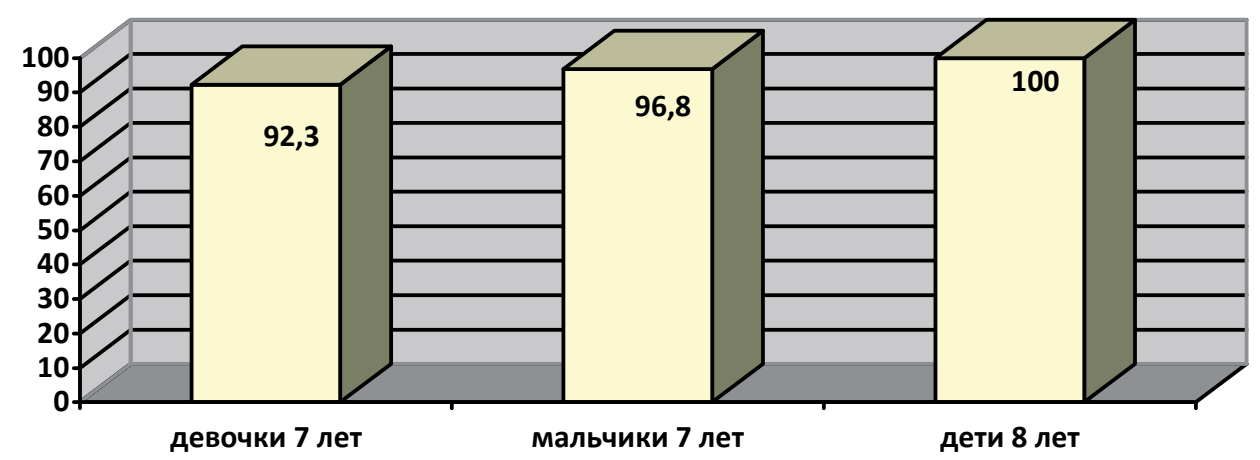

Рис. 1. Структура прорезывания первых постоянных моляров у детей 7-8 лет в \% 


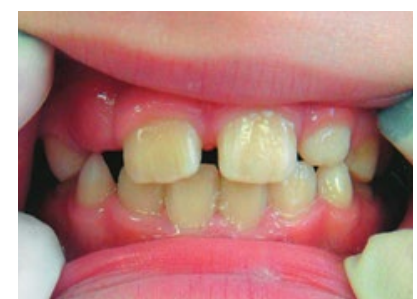

Рис. 2. Несимметричное прорезывание зубов 1.2, 2.2, нарушение физиологической стираемости временных клыков у ребенка 8 лет

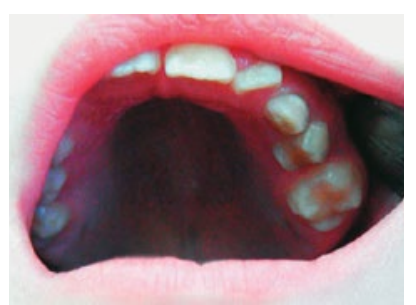

Рис. 3. Мезиальное смещение зуба 2.6 у ребенка 8 лет в результате раннего удаления зуба 6.5 и отсутствия протезирования

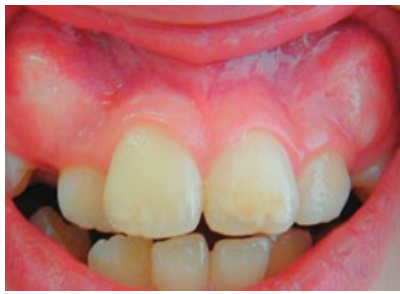

Рис. 4. Дефицит места для прорезывания постоянных клыков верхней челюсти у девочки 11 лет

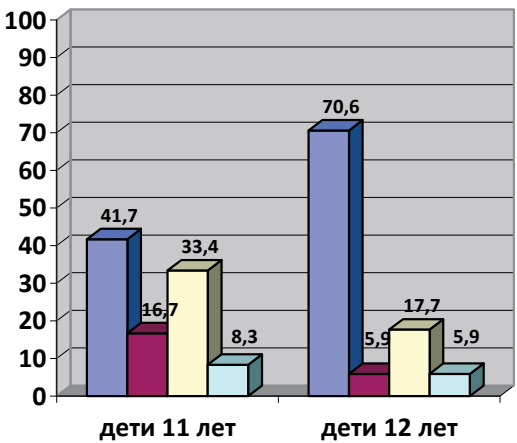

$\square$ Ранний постоянный
прикус
$\square$ Сменный-ІІ прикус -
1 молочный зуб
$\square$ Сменный-II прикус -
2 и более молочных
зубов
$\square$ Сменный-ІІ прикус -
отсутствие
молочных зубов

Рис. 5. Структура смены зубов у детей 11-12 лет

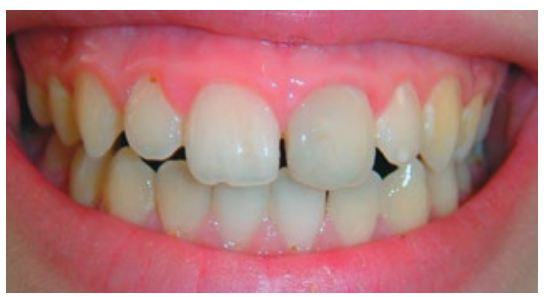

Рис. 6. Ранний постоянный прикус у мальчика 12 лет

смены зубов. При смене боковых резцов верхней челюсти определяется нарушение симметричности. Преждевременное прорезывание премоляров нарушает последовательнось и парность смены зубов. А смещение зубов, происходящее в результате раннего удаления, сокращает протяженность опорной зоны, что приводит к дефициту места для прорезывания постоянных клыков (рис. 4).
По данным Виноградовой Т.С. [3], у детей 11-12 лет должна происходить смена первых и вторых премоляров обеих челюстей, а также начинаться смена клыков, возраст прорезывания для которых - 12-13 лет, по данным этого автора.

При осмотре детей старшей группы выявлено, что прорезывание всех постоянных зубов опорной зоны в различной степени произошло в 41,7\% случаев у детей 11 лет. При оценке количества сохранившихся молочных зубов у 11-летних детей 1 молочный зуб сохранен в 16,7\% случаев, 2 и более зуба - в $33,4 \%$ случаев. В $8,3 \%$ случаев молочные зубы не определялись, но прорезывание постоянных еще не произошло (рис. 5).

У 12-летних детей прорезывание всех постоянных зубов опорной зоны определено в 70,6\% случаев. Количество сохранившихся молочных зубов у детей этого возраста ниже: 1 молочный зуб $-5,9 \%, 2$ и более молочных зуба - 17,7\%. В 5,9\% случаев молочные зубы не определялись, но прорезывание постоянных еще не произошло (рис. 5, 6).

В 97,6\% случаев у детей старшей группы симметричность, парность и последовательность смены зубов опорной зоны была нарушена.

Интенсивность кариозного процесса у детей старшей возрастной группы низкая, составляет 1,36. Гигиена полости рта по показателю ИГР-У - 1,21 - также на более высоком уровне по сравнению со значением данного показателя в младшей группе.

Таким образом, анализ приведенных данных свидетельствует об опережении сроков прорезывания постоянных зубов в период позднего сменного прикуса в сравнении с данными Т.С. Виноградовой, при этом практически у всех детей определяется нарушение симметричности, последовательности и парности прорезывания.

Сочетание вышеизложенных особенностей смены зубов в период раннего и позднего сменного прикуса могут создавать предпосылки к раннему формированию ретенции клыков верхней челюсти. Так, у пациентки 11 лет нами уже была диагностирована ретенция зуба 2.3. Пациентка была направлена на прием к врачу-ортодонту после удаления зуба 6.3 по санационным показаниям. Несмотря на регулярные посещения ребенком детского стоматолога, более раннего удаления персистентного зуба проведено не было. При оценке состояния зубочелюстной системы обращает на себя внимание ранняя смена зубов, что указывает на смещение сроков смены зубов у данного ребенка по сравнению с литературными данными. Отсутствие прорезывания зуба 2.3 является нарушением симметричности и парности смены зубов (рис. 7). 
Для определения локализации ретенированных и сверхкомплектных зубов использовали методику анализа ОПТГ Ю.И. Жигурта (1994) [6]. Зуб 2.3 располагается в толще кости, корень на завершающей стадии формирования. Продольная ось 2.3 зуба образует угол с горизонтальной плоскостью более чем $120^{\circ}$, что соответствует третьей, наиболее тяжелой степени положения комплектных ретенированных зубов (рис. 8).

Уровень расположения бугра ретенированного зуба соответствует III полю по методике Ю.И. Жигурта. III и IV уровни расположения являются наиболее удаленными от гребня альвеолярного отростка и, следовательно, оцениваются как менее благоприятные для прогнозирования лечения (рис. 9).

Диагноз: Физиологическая окклюзия, дистопия и ретенция зуба 2.3 .

Планируется проведение ортодонтического лечения на брекет-системе с хирургическим обнажением коронки зуба 2.3, последующей экструзией его в зубной ряд. Ориентировочный срок лечения - 2 года.

\section{Выводы}

1. Анализ состояния зубочелюстной системы у детей города Екатеринбурга определил нарушение всех закономерностей естественной смены зубов у большинства обследуемых.

2. Имеется тенденция смещения сроков прорезывания зубов к более раннему возрасту. Причиной этого могут являться как общие (явление акселерации), так и местные факторы (высокая интенсивность кариозного процесса и раннее удаление молочных зубов).

3. Для проведения скрининга нарушений закономерности естественной смены зубов необходимо проведение панорамных рентгеновских снимков (ОПТГ) детям в возрасте 7 и 9 лет.

4. При выявлении нарушений закономерностей естественной смены зубов необходимо назначение детским стоматологом или врачом-ортодонтом корректирующих мероприятий.

\section{ЛИТЕРАТУРА}

1. Волчек Д.А. Оптимизация лечения пациентов с ретенцией клыков на верхней челюсти: автореф. дис. ... канд. мед.наук // АО «Стоматология». - М, 2007. - 35 С.

2. Герасимов С.Н., Рядченко В.Н. Ретенция верхнечелюстных клыков // Институт стоматологии. - 2002. - №3. - С. 30-35.

3. Детская терапевтическая стоматология. Национальное руководство / Под ред. В.К.Леонтьева, Л.П.Кисельниковой. - М.: ГЭОТАР-Медиа, 2010. - С. 71-75.

4. Жан-Мари Корбандо. Хирургическое и ортодонтическое лечение ретенированных зубов/ Ж.-М.Корбандо, А.Патти. - М: Азбука, 2009. - 135 с.

5. Жан Ю.Э. Ретенция клыков у детей (диагностика и комплексное лечение): автореф. дис. ..... канд. мед. наук // АО «Стоматология». - М., 2013. - 21 с.

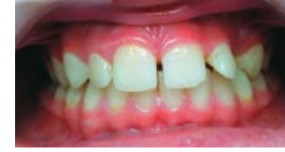

a

厂

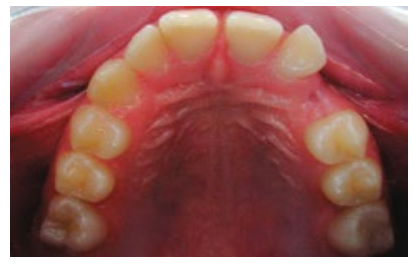

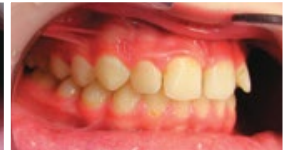

6

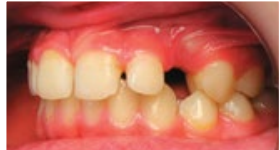

B

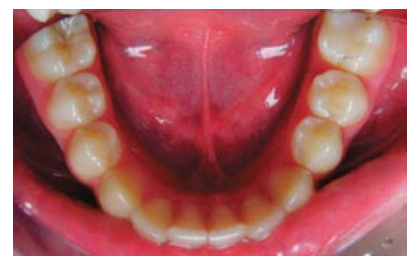

д
Рис. 7. Окклюзия и зубные ряды пациентки на момент обращения: а - вид в прямой проекции, б - вид в боковой проекции справа, в - вид в боковой проекции слева, г - верхний зубной ряд, д - нижний зубной ряд

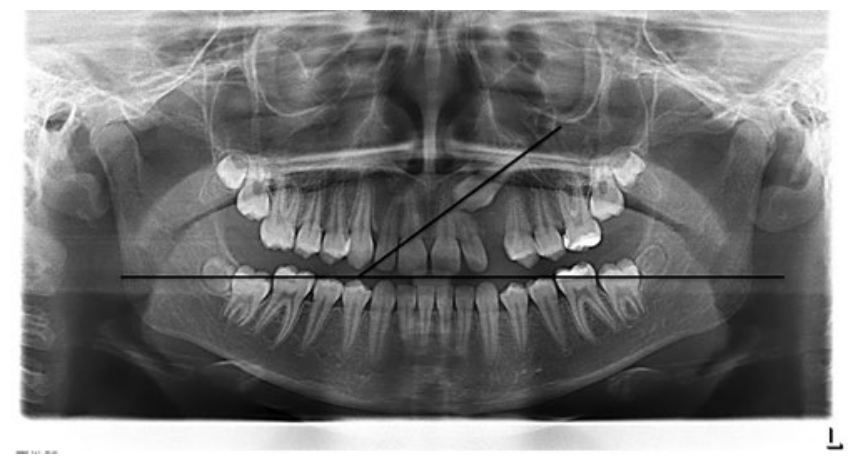

Рис. 8. Ортопантомограмма пациентки 11 лет с ретенцией зуба 2.3 с углом наклона ретенированного клыка верхней челюсти $130^{\circ}$

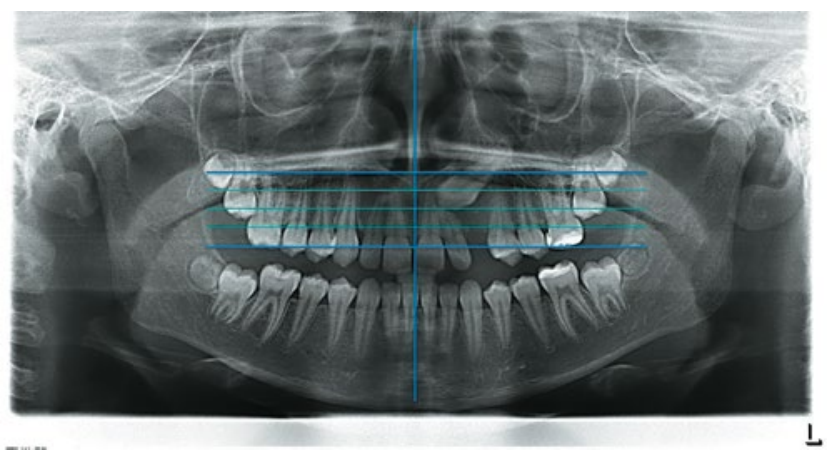

Рис. 9. Ортопантомограмма пациентки 11 лет: расположение ретенированного зуба соответствует III полю по методике Ю.И. Жигурта

6. Жигурт Ю.И. План и прогноз лечения при ретенции зубов: автореф. дис. ..... канд. мед. наук // АО «Стоматология». - М. - 1994. - 23 c.

7. Персин Л.С. Ортодонтия. Современные методы диагностики зубочелюстно-лицевых аномалий: Руководство для врачей. - М.: 000 «ИЗПЦ «Информ-книга», 2007. - 248 с.

8. Особенности диагностики и лечения подростков с ретенцией клыков верхней челюсти / Мягкова Н.В., Бимбас Е.С., Бельдягина М.М., Ярушина М.О. // Проблемы стоматологии. - 2013. - №5. - C. 42-46. 